All you need to do is to recognise that the reason you are where you seem to be is

all down to your perception and your

beliefs.

\section{Who's in control?}

Control is a fascinating subject; being in control even more so. Feeling out of control is one of the major sources of stress (so we are told), yet we see very little on how to manage the perception of control, and the feeling of being out of control is based on perception. In dentistry stress is a common problem, for both dentists and patients (let alone the rest of the team) so why do we see so little written on the actual perception of stress rather than the reality?

The degree of stress in dentistry was brought home to me after I organised a practical workshop on stress control. All the delegates received a small monitoring device you can attach to your fingertip to measure your stress level. I remember one of the delegates later confided in me that he wore the device for a whole day, and was really surprised to discover his stress level was at its highest just before each patient was shown into the surgery, yet he was completely unaware of this until he wore the monitoring device.

To return to the concept of control - I am certain that most people are unaware of just how much control they actually have in their lives. In fact I suspect the common perception is that we have less and less control, and it seems to be reducing all the time. My conclusions come from the reaction I get when speaking to dentists on courses I have organised on time-management. My first question is always the same: I ask the audience how many people feel totally in control of their time. The reason for this is simple. If you feel you are not in total control of your time then how can you successfully manage it?

I hardly ever remember anyone in the audience (and this is over many years) admitting they do feel in complete control of their time ... at least not at first. Even when I initially tell them that they really are, most people still do not believe me. When I ask them who does control their time then - I start to get a slow realisation from one or two. When I explain that they really can decide exactly how they wish to spend their time: it is just a question of choices; then a few more understand. Some never do.

One model of control is called 'Locus of control' and refers to the perception of the amount of control we believe we have over our lives. A high internal locus of control refers to a belief that we are basically masters of our fate most of the time. A high external locus of control refers to the belief that external events and people control us and we have very little choice is deciding our future. Neither is right, it simply reflects our current belief and the range of what we believe tends to move along a straight line from high external to high internal all the time, depending on circumstances. However, we do tend to have a certain natural leaning towards one belief or the other.

Along with locus of control goes locus of responsibility, which refers to our belief on how much responsibility we have. High internal refers to a belief that we are basically responsible for our actions and the effects on others, while high external means we believe that other people and external events are to blame. Thus a person with a high external locus of responsibility always blames the traffic, the weather, the government or whoever for the situation when things go wrong. Interestingly, they also find it difficult to accept praise for a job well done, preferring to assume they were just lucky when things go well.

If you now combine the two loci together you get four possible belief scenarios: people with high external control and high external responsibility; people with high internal beliefs for both; people who have high internal control but high external responsibility; and then those poor souls who have a high external locus of control but a high internal locus of responsibility. In other words, they think they have very little control over things but when things go wrong then they are to blame. This is not a good place to be.

Which brings me finally to the point of this leader. If you are one of the people in this last category then you are probably not happy, possibly stressed, and wondering how to cope in the future (which seems to apply to quite a few dentists at the moment in view of the current political situation). The answer to this may be simple, but is not easy. All you need to do is to recognise that the reason you are where you seem to be is all down to your perception and your beliefs. Change those, and you change your perception of the control you have. Change your perception and you change your reality.

It may sound a bit heavy, but it works.

Mike Grace, Editor m.grace@bda.org

doi: 10.1038/sj.bdj.4811611 